\title{
Editorial
}

\section{Policy shifts and curriculum effects}

\author{
Jane Abbiss \\ https://doi.org/10.18296/cm.0033
}

Curriculum is political. It is political in the sense that official curricula are policies that are approved by governments and used by them as levers for educational change. Curriculum policy also sits within and is part of a broader educational policy landscape that influences funding and the operation of schools and early childhood centres and what is taught and learnt in compulsory and early years education. These policies have a normative dimension in the way that they imply a view about what is valued and what ought to be done (Roberts, 2019). Power is exercised in the development, roll-out and implementation of curricula and educational policies and in the manner in which teachers may enact or resist policy elements that are designed to shift teaching practise and the nature of learning early childhood centres and schools. Curriculum is also political in a broader sense, in the way that curriculum-related issues invoke debate because they are things that people are interested in and about which they hold views on what is important and what ought to happen.

Recent policy announcements in Aotearoa New Zealand and ongoing reviews relating to the schooling sector, specifically the NCEA Review (Ministry of Education, n.d.b) and associated proposed NCEA Change Package 2019 and the Tomorrow's Schools Review (Ministry of Education, n.d.c) highlight the influence of the education policy landscape on curriculum. Neither of these major reviews are explicitly about curriculum revision and there is currently no associated, formal revision of the official school curricula underway. However, both of these government instigated reviews have potential to impact the curriculum significantly, by influencing what is taught and learnt through the curriculum in practice, in some ways that may be already obvious and in other ways that are not yet apparent. At this stage any ideas about particular effects on teaching and learning programmes 


\section{Editorial}

are conjecture, but understanding the role of policy and the relationship between curriculum and assessment suggest that these policy initiatives will influence the curriculum in practice and experienced by àkonga (learners).

The NCEA Change Package will alter the focus for assessment and ākonga learning in the senior secondary school as the achievement standards for subjects are redeveloped with a view to having fewer and broader standards for assessment (Ministry of Education, 2019a). As a de facto curriculum, the National Certificates of Educational Achievement (NCEA) have a powerful influence on teaching and learning, through the requirements placed on learners in order for them to meet particular assessment requirements, as specified in subject achievement standards and the broader qualification structure and rules relating to credit acquisition at different levels. There will likely also be effects on curriculum in earlier years through the "washback" and powerful influence of assessment structures on curriculum that are features of the curriculum-assessment relationship (Abbiss, 2019) and which are clearly documented (see for example, Mizutani, Rubie-Davies, Hattie, \& Philp, 2011; Taylor, 2011; Thrupp, 2018).

While the Tomorrow's Schools Review is primarily concerned with systems level reform related to governance, management, and administration of schools, elements of the review have the potential to influence curriculum. Any changes relating to who gets to influence school-level decisions will have an effect on the school-based curriculum. Take, for example, the government decision to create a curriculum centre to provide curriculum leadership and expertise (with alignment to The New Zealand Curriculum [NZC], Te Marautanga o Aotearoa [TMOA] and NCEA assessment) that is part of the Tomorrow's Schools reform. The shape of the proposed centre is yet to be determined, but the decision signals an intention to pull back some curriculum advice and support functions into a centralised agency and potentially a shift in the "tight-loose" balance relating to curriculum decision making. The "tight-loose" concept relates to the simultaneous regulation of teaching and learning through curriculum and assessment mechanisms and the enabling of local decision making and variations in the curriculum in practice that are responsive to learners and local contexts (Abbiss, 2019; Thompson \& Wiliam, 2007). Teachers will retain a high level of autonomy and responsibility for curriculum decision making but the centre will provide a mechanism to influence that decision making by providing 
curriculum leadership and expertise to support teachers to "interpret them [NZC and TMOA curricula], ensure they are relevant in a local context, and bring them to life in the classroom" (Ministry of Education, 2019c. p.33). It appears that an intention is to create tighter alignment between the curriculum in practice and curriculum policy intentions. If implemented, this organisational change will impact what is taught and learnt-perhaps not as directly or powerfully as proposed NCEA assessment changes, but there will be effects nonetheless.

These two reviews are not the only curriculum-related "conversations" that are being had by government with a view to policy changes. There is, for example, a Curriculum, Progress and Achievement Ministerial Advisory Group (Ministry of Education, n.d.a) that has been established to provide direction on the future of curriculum, teaching, and learning in Aotearoa New Zealand. Recommendations from the group include, amongst a range of suggestions, the review of TMOA, establishing a timeframe for ongoing review of $N Z C$, clarifying the role and purpose of local curricula in relation to $N Z C$, and designing and trialling rich records of learning and different approaches and tools for assessment in relation to curriculum progress maps (Ministry of Education, 2019b). Recognising the political nature of curriculum suggests that these proposals and other shifts in curriculumrelated policies and processes will be a source of debate and critique as the implications of the policy shifts become clearer.

Educational researchers ask questions about the purpose, efficacy, and desirability of particular policies that shape the curriculum in its different forms, including the official curriculum and the curriculum in practice in schools and centres. The articles in this edition of Curriculum Matters illustrate how policies that direct particular courses of action are contestable and how engagement with policy contexts and the relationship between policy and practice can result in the reframing of curriculum issues. They are a useful reminder of the importance of engaging critically with shifts in policy and practice as governmental reviews related to school management and assessment move towards implementation and other curriculum-related reviews are proposed-to provide deep understanding on which positions can be taken in support of or to challenge particular policy directions and their curriculum-related impacts. 


\section{Editorial}

\section{This collection}

Contributions in this collection includes four research articles and a special section on global citizenship education.

The four research articles highlight the contestability of particular policies as the authors engage with curriculum-related issues. Although they deal with very different topics - ranging across the representation of inequity in $N Z C$, the shift in schools towards flexible learning spaces and collaborative teaching, culturally responsive practice and Māori achievement, and the role of school libraries and librarians in curriculum delivery - they all engage with policy in some way. The authors examine particular curriculum policies, identify challenges for education professionals in implementing policies, or question the efficacy of particular courses of action and the ability of curriculum initiatives to effect the desired change.

Jennifer Tatebe, Acacia Cochise and Andrea Edwards analyse the NZC and curriculum teaching support materials at the secondary-school level to identify how the idea of inequity is represented within the curriculum in secondary-school subjects. Their analysis leads them to focus particularly on how teaching about financial literacy and financial capability are employed to present particular views on inequality. They highlight the way that inequity is examined within Social Science subjects and indicate concerns with particular ideological influences and the limited view of inequity that is presented in the curriculum, which they argue emphasises personal financial responsibility and largely fails to acknowledge of the structural reasons for social and economic inequality. Implications that might be drawn from their work are that understanding of inequity needs to be reframed within curriculum to have a broader and more critical view of society, historical context, and economic policies.

Focusing on Ministry of Education building policy that supports the development of innovative learning environments (ILEs) and a move towards collaborative teaching and reorganisation of curriculum for the 21st century, Megan Taylor identifies a lack of attention and limited research base for the policy in relation to secondary schooling. She characterises this as a blind spot. While substantial reorganisation of curriculum at the school level is acknowledged as a way of achieving 21 st-century education aspirations, Taylor questions whether radical reorganisation of the curriculum into 
cross-subject models is a necessary path to achieve these aspirations. A call is made for more research into curriculum models in secondary school ILEs to illuminate the blind spot, inviting clearer framing of issues relating to teaching in ILEs in secondary schooling contexts.

Jacek Krzyzosiak and Georgina Tuari Stewart ask if culturally responsive policies can improve Māori achievement. Based on an examination of culturally responsive and bicultural policies to improve Māori educational outcomes, they present an argument that culturally responsive practices should not be seen as the solution to Māori underachievement. Although it is important for teachers and schools to enact curriculum in ways that are culturally responsive, inequity in Māori achievement needs to be understood more broadly and in relation to the historical development of Māori education policy and the effects of large-scale socio-economic processes and disadvantage. They make the case that focusing of culturally responsive practice as the solution to raising Māori achievement tends to place responsibility with schools and teachers and deflects responsibility from the policy itself and from government.

In the fourth of the research articles, Lisa Emerson and the nine other members of the research team report on a survey of secondary-school teachers and librarians relating to perspectives on information literacy. The survey is partly a response to the positioning of information literacy in the background of $N Z C$ and a lack of explicit information literacy goals in the curriculum and concern the authors fell at a lack of attention to integration of library services in curriculum delivery. A gap is perceived between a policy intention to deliver quality library services in secondary schools and a reported situation of library services that are not fully effective or fully integrated into the curriculum. Findings from the survey confirm that library services are not fully integrated into curriculum delivery and that teachers and librarians see the function of libraries differently. The researchers call for systemic change and a review of library services to help reset beliefs about library services and for the role of the library and librarians to be understood more broadly and reframed in relation to information literacy in the curriculum.

The special section includes five position papers on global citizenship education, prepared for the New Zealand National Commission for UNESCO on global citizenship education, a meeting for which was held in 


\section{Editorial}

August 2019. The five papers represent five perspectives on global citizenship education-academic (Bronwyn Wood), Māori (Sonja Macfarlane), Pasifika (Jacoba Matapo), teacher (Maria Perreau) and youth (Peter McKenzie). Global education is part of the policy agendas for transnational organisations, including the OECD and UNESCO. The OECD advocates for incorporation of global competence in curriculum, instruction and assessment (OECD, 2018) and UNESCO presents itself as having a role in providing global and regional leadership in education and leading a program for global education. Themes that provide a focus for UNESCO's work include global citizenship and sustainable development (UNESCO, n.d.). In focusing on global citizenship education, a question that might be asked is how global citizenship education sits in relation to these policy agendas. In her overview of the special section, Carol Mutch asks whether global citizenship education represents a fresh approach to engaging children and young people in global issues or it merely inducts them into a world view dominated by neoliberal and global interests. In considering different perspectives on and ideas about global citizenship education, the authors of the position papers address the global policy direction and how it can be made sense of in the Aotearoa New Zealand context. They offer up questions and challenges for the enactment of global citizenship education and how this might be shaped by teachers and experienced by learners.

Together, the research articles and position papers illustrate the importance of understanding curriculum issues in policy contexts and of critical engagement with policy and practice and the normative assumptions contained therein about what ought to be taught and learnt and how this should be done.

\section{References}

Abbiss, J. (2019). Curriculum studies. In A. Kamp (Ed.), Education studies in Aotearoa: Key disciplines and emerging directions (pp. 112-132). Wellington, New Zealand: NZCER.

Ministry of Education (n.d.a). Conversation: Curriculum, progress and achievement. Retrieved from: https://conversation.education.govt.nz/conversations/curriculumprogress-and-achievement/

Ministry of Education (n.d.b). Conversation: NCEA review. Retrieved from: https:// conversation.education.govt.nz/conversations/ncea-review/ 
Ministry of Education (n.d.c). Conversation: Tomorrow's Schools review. Retrieved from: https://conversation.education.govt.nz/conversations/tomorrows-schools-review/

Ministry of Education (2019a). NCEA Change Package 2019: Overview. Wellington, New Zealand: Author.

Ministry of Education (2019b). Strengthening curriculum, progress, and achievement in a system that learns. E whakakaha ana i te marautanga, te koke, me te ekenga taumata $i$ te rangapū e ako ana. A report by the Curriculum, Progress, and Achievement Ministerial Advisory Group. Wellington, New Zealand: Author.

Ministry of Education (2019c). Supporting all Schools to Succeed: Reform of the Tomorrow's Schools System. Wellington, New Zealand: Author.

Mizutani, S., Rubie-Davies, C., Hattie, J., \& Philp, J. (2011). Do beliefs about NCEA and its washback effects vary depending on subject? New Zealand Journal of Educational Studies, 46(2), 47-59.

OECD (2018). Teaching for global competence in a rapidly changing world. https://doi. org/10.1787/9789264289024-en

Roberts, P. (2019). Philosophy of education. In A. Kamp (Ed.), Education studies in Aotearoa: Key disciplines and emerging directions (pp. 25-46). Wellington, New Zealand: NZCER.

Taylor, R. (2011). Trickle-down effects: How have developments in senior secondary school social studies shaped practice in junior secondary social studies? Curriculum Matters, 7, 195-212.

Thompson, M., \& Wiliam, D. (2007, April). Tight but loose: A conceptual framework for scaling up school reforms. Paper presented at the annual meeting of the American Educational Research Association (AERA), Chicago. Retrieved from: https://www. dylanwiliam.org/Dylan_Wiliams_website/Papers.html

Thrupp, M. (2018). The search for better educational standards: A cautionary tale. Cham, Switzerland: Springer.

UNESCO (n.d.). Education transforms lives. Retrieved from https://en.unesco.org/ themes/education/ 